\title{
Gênero, cultura e deslocamentos: uma pequena história e muitas inquietações
}

Gender, culture and displacements: a little history and many concerns

Raimunda Gomes da Silva1, Mariana Cunha Pereira², Francisco Marcos Mendes Nogueira ${ }^{3}$, Alessandra Rufino Santos ${ }^{4}$, Alexandre Adalberto Pereira ${ }^{5}$ e Maria Lúcia da Silva Brito 6

1 Universidade Estadual de Roraima (UERR), curso de História, Programa de PósGraduação em Educação (PPGE) e Mestrado Profissional em Ensino de História (PROFHISTÓRIA), Brasil, E-mail: silvaraimunda@uerr.edu.br, ORCID: https://orcid.org/0000-0002-0835-2110

2 Universidade Federal de Roraima (UFRR), curso de História, Programa de PósGraduação em Antropologia Social (PPGANTS) e Mestrado Profissional em Ensino de História (PROFHISTÓRIA), Brasil, E-mail: marianac.pereira@ufrr.br, ORCID: https://orcid.org/0000-0002-1871-5595

3 Universidade Federal do Rio Grande do Sul (UFRGS), Brasil, E-mail: marcos2201@gmail.com, ORCID: https://orcid.org/0000-0002-1630-5613

${ }^{4}$ Universidade Federal de Roraima (UFRR), curso de Educação do Campo e Mestrado Profissional em Ensino de História (PROFHISTÓRIA), Brasil, E-mail: alessandra.santos@ufrr.br, ORCID: https://orcid.org/0000-0002-8326-3492

${ }^{5}$ Universidade Federal do Amapá (UNIFAP), curso de Artes Visuais e Programa de Pós-Graduação em Educação (PPGED), Brasil, E-mail: pereiraxnd@gmail.com, ORCID: https://orcid.org/0000-0003-4029-1415

${ }^{6}$ Universidade Federal de Roraima (UFRR), Colégio de Aplicação (CAp), Brasil, Email: mlubrito07@gmail.com, ORCID https://orcid.org/0000-0003-3979-7056

A R T ICLE IN F O

Article history:

Received 2021-06-30

Accepted 2021-08-02

Available online 2021-08-02
Palavras-chave: Gênero. Cultura. Deslocamentos.

Keywords: Gender. Culture. Displacements.

A temática Gênero, Cultura e Deslocamentos tem algumas motivações relacionadas ao contexto de extremo Norte da Amazônia/Brasil, particularmente a cidade de Boa Vista, capital do estado de Roraima. A maior parte das terras de Roraima limita-se com a República Bolivariana da Venezuela e a República Cooperativista da Guiana (IBGE, 1991). Pode-se dizer que trata de um lugar configurado como pequeno laboratório em movimento constituído por população indígena de diferentes etnias e não indígena, formada por roraimenses, filhos de migrantes de várias federações do país com destaque de nordestinos, particularmente os maranhenses. 
Em outras palavras, Roraima constitui um espaço que, nos últimos anos, tem mudado a configuração com grande quantidade de migrantes, principalmente, da Venezuela. Tal cenário de diversidade social e cultural, de forma direta ou indireta, tem proporcionado inquietações uma vez que se percebe no cotidiano da cidade reações diversas, como estranhamento e xenofobia, aos(às) migrantes na rua, no trabalho, nos espaços comerciais, nas escolas, dentre outros lugares. Mas também possibilidades de olhares de pesquisadores(as) e professores(as) diante do contexto de diversidade social e cultural.

Considerando este movimento de certa pluralidade, Laclau (apud HALL, 2005) expõe que as conexões com as mudanças relacionadas às transformações sociais e culturais provocadas com a "modernidade tardia" são caracterizadas pelas 'diferenças'; elas são atravessadas por diferentes divisões e antagonismos sociais que produzem diferentes 'posições de sujeitos,' isto é identidades (HALL, 2005, p.17). Tais categorias se constroem e reconstroem de forma dinâmica, sejam regionais e étnica, sexual e de gênero, compreendendo um contexto social de aparentes práticas flexíveis em que "os sujeitos são fluidos e se constroem no transcurso de complexas histórias, [...] são construídos no interior de jogos de poder e estão implicados nas operações de inclusão ou exclusão" (TEDESCHI, 2013, p. 84).

Pedro (2011, p.206), ao se reportar as mulheres brasileiras, observa novas formas de feminilidade em diferentes seguimentos e argumenta que

Las mujeres se pensaron como capaces de construir carreras propias y exigir relaciones más igualitarias con sus parejas. Estas nuevas prescripciones, evidentemente, no serán asumidas por todas, por lo que muchas mujeres vivirán estas nuevas formas de femineidad sin identificase con el feminismo, viviendo todo esto en forma individual, como una elección al interior de las innumerables prescripciones que estaban siendo constituidas en la época.

Pode-se observar, nos argumentos de Pedro (2011), transformações na vida das mulheres conjugadas com as lutas feministas e consolidação da História das Mulheres, corroborando com o pensamento de Matos, (2000, p.14):

[...] Num leque de várias correntes de interpretações, procurouse recuperar a atuação das mulheres no processo histórico como sujeitos ativos, de modo que as imagens da pacificidade, ociosidade e confinação ao espaço do lar vem sendo questionadas, descortinando-se as esferas de influência e recuperado os testemunhos femininos.

De acordo com o contexto apresentado, mudanças sociais e culturais, teóricas e metodológicas proporcionam outras histórias das mulheres. Referindo-se a Roraima, a implantação das universidades, que proporcionou qualificação e ampliação de olhares para outros sujeitos e temáticas, possibilitou leituras mais críticas e propositivas. Permitiu, ainda, debates qualificados e relacionados à educação,à história e/ou a áreas afins, no sentido de favorecer a diversidade social e cultural de forma afirmativa com olhar de gênero. 
Foi dentro destas inquietações e vontade de provocar outras reflexões, outras histórias, práticas pedagógicas e relações de gênero, que o Grupo de Estudo Gênero, Cultura e Deslocamentos surgiu no ano de 2018, com o objetivo de reunir pesquisadores(as), estudantes de graduação e de pós-graduação de formações distintas, interessados(as) em estudar gênero, cultura e deslocamentos. Essas categorias pareciam urgentes diante do contexto de diversidade do cenário plural do extremo Norte da Amazônia, sobretudo, nas demandas das escolas.

O grupo foi formado por docentes e acadêmicos(as) da graduação em História, da Pós-Graduação, Especialização em História da Amazônia e do Programa de PósGraduação em Educação da Universidade Estadual de Roraima em convênio com o Instituto Federal de Educação Ciência e Tecnologia de Roraima (PPGE/UERR/IFRR), do Mestrado Profissional em Segurança Pública, Direitos Humanos e Cidadania (MPSPDHC). Atualmente, o grupo se constitui de mestrandos(as) e docente de História, vinculado ao PPGE; mestrando do (MPSPDHC) e Pedagogia da UERR; docentes dos cursos de História e de Educação do Campo, vinculados ao Mestrado Profissional em Ensino de História (PROFHISTÓRIA/UFRR).

Quanto às três categorias centrais do grupo, são exploradas de forma interdisciplinar, por meio de diferentes leituras envolvendo gênero como categoria de análise histórica segundo Joan Scott. Sendo gênero "um elemento construtivo de relações baseadas nas diferenças entre os sexos e o gênero é uma forma primeira de ressignificar as relações de poder. (...)" (SCOTT, 1996, p.11). E deslocamentos, a partir de Abdelmalek Sayad, compreendido como um "fator social completo (políticos, econômicos, sociais e culturais), principalmente dentro da perspectiva cultural" (SAYAD, 1998, p.15). Estas duas perspectivas de olhares têm auxiliado nas leituras e reflexões do grupo em conjunto com outros autores(as) que abordam esta temática no campo da História e Educação. Elas têm auxiliado também em ações acadêmicas que ampliem as dicussões de forma interdiciplinar, sendo a Jornada de Gênero, Cultura e Deslocamentos o mais importante evento do grupo.

A iniciativa da I Jornada de Gênero, Cultura e Deslocamentos teve por finalidade divulgar o grupo e provocar debates sobre as questões de gênero na comunidade acadêmica e movimento social, visando à ampliação de possibilidades de integração destes(as) pesquisadores(as), lideranças e docentes entre si e com o GT Gênero, Cultura e Deslocamentos, a fim de somar forças, saberes e estratégias em direção a uma cultura política crítica e qualificada. De forma que, tanto possibilite espaço de incentivo a iniciação cientifica e promova atividades de pesquisa, ensino e extensão quanto aglutine novos(as) pesquisadores(as), mestrandos do Mestrado do PPGE e MPSDHC da UERR, do (PROFHISTÓRIA/UFRR) dentre outros(as) pesquisadores(as) de outras instituições interessados(as).

A II Jornada de Gênero, Cultura e Deslocamentos realizada em abril de 2021, de forma online, teve como objetivos propiciar estudos e debates de forma propositivas, bem como proporcionar espaço de debates, estudos, reflexões críticas e propositivas sobre as relações de gênero em diferentes níveis de deslocamentos contemporâneos, especialmente no contexto atual da política fascista, que interdita o processo sócio-histórico da construção de uma sociedade democrática e plural em que haja pesquisadores(as), estudantes de graduação, pós-graduação, ativistas interessados(as) em enriquecer as discussões, suscitar outros olhares e novas possibilidades de se pensar as práticas de ensino, pesquisa e extensão, seja no campo da história e/ou da educação, a partir da abordagem de gênero, da cultura e dos deslocamentos humanos.

Dessa forma, o volume da REVES - Revista de Relações Sociais ora apresentado assume o compromisso de ampliar leituras e romper barreiras impostas 
a essas dimensões relacionadas às questões de Gênero, Cultura e Deslocamentos. Os artigos aqui publicados foram organizados à luz dos três eixos temáticos: "Gênero, Identidades e Deslocamentos", "Gênero, Educação e Sexualidade", e "Estudos de Gênero - possibilidades metodológicas".

O primeiro eixo temático "Gênero, Identidades e Deslocamentos" discute a dinâmica de construção, manutenção, transformações e/ou ressignificações das identidades territoriais a partir da perspectiva de gênero numa relação com a espacialidade humana. Em seguida, o segundo eixo temático "Gênero, Educação e Sexualidade" apresenta complexidades do fazer pedagógico e respeito às diferenças, em meio à necessidade de ampliar o debate, de forma reflexiva e a partir de uma perspectiva crítica, sobre as questões de gênero e sexualidade de modo a possibilitar a educação inclusiva. Na sequência, o terceiro eixo temático "Estudos de Gênero possibilidades metodológicas" repensa os métodos e técnicas em pesquisa de gênero em um diálogo com a história oral, dando ênfase a descrição do objeto, como também o uso de fontes e tratamento dos dados.

Chegamos à II Jornada de Gênero - cultura e deslocamento cientes de estar cumprindo um papel e assumindo um lugar de produção do conhecimento no espaço acadêmico de Roraima. Discutir cultura e deslocamento em uma região de fronteira é um propósito bastante articulado à realidade local. Ainda mais quando entendemos que esses deslocamentos são provisórios, são pendulares, são interétnicos e, também, são plurais em suas composições interétnica. Nesse sentido, é mister explicar que a fronteira enquanto espaço geopolítico desses deslocamentos é também, trocas culturais, trânsitos interétnicos e espacialidades construídas por significados dos povos da fronteira (PEREIRA, 2005).

A cultura nas discussões desse grupo de pesquisa é entendida segundo a visão interpretativista de Geertz (1980), a perspectiva estruturalista de Da Matta (1981; 1999); os aportes da História Cultural (CHARTIER, 1990; PENSAVENTO, 2005; da Educação CANDAU, 2008) entre tantos autores que promovem a discussão do que é cultura. Assim, cultura é uma teia de significados, um modo de ser, uma criação humana que dá sentido a relação homem - natureza. A cultura produz processos educativos que são repassados de geração a geração e, em última análise, constrói o senso comum e influência o arcabouço teórico dos conhecimentos históricos produzidos na sociedade e sobre ela. Os textos expostos nessa Jornada comprovam isso, por meio das discussões sobre festas ou da história de vida que traz a trajetória de um sujeito social, das explicações de cada escala, local ou global, em que as identidades são identificadas ou naqueles textos em que a educação formal ou informal traduz os signos e os símbolos com os quais se aprende, se vive e interpretamos a vida. $E$, mesmo que um texto trate da violência, da sexualidade ou do modo como se percebe o idoso, ainda assim, estamos tratando de cultura.

As discussões das categorias expostas anteriormente articuladas a abordagem de gênero podem contribuir para descortinar outros sujeitos, promoção da educação intercultural e, por conseguintes outras histórias no contexto do extremo norte da Amazônia. Para além disso, a realização do evento, no formato remoto, possibilitou alargar os diálogos, debates e visibilidade de diferentes pesquisadores(as) de vários estados do Brasil, inclusive não podemos deixar de citar a participação de dois pesquisadores do Uruguai.

Apesar de algumas lacunas, consideramos importante levar a público as contribuições de parte dos pesquisadores participantes da II Jornada de Gênero, Cultura e Deslocamentos. 


\section{Agradecimentos}

Agradecemos a colaboração dos integrantes do Grupo de Estudo Gênero, Cultura e Deslocamentos e o convite de publicação recebido da REVES - Revista de Relações Sociais, sem a qual esta publicação dificilmente se tornaria realidade.

\section{Referências}

CANDAU, Vera Maria. Direitos humanos, educação e interculturalidade: as tensões entre igualdade e diferença. Revista Brasileira de Educação. v. 13 n. 37 jan./abr. 2008.

CHARTIER, Roger. A história cultural: entre prática e representações. Rio de Janeiro: Difel, 1990.

DA MATTA, Roberto. Você Tem Cultura?. Jornal da Embratel, RJ, 1981.

DA MATTA. (1999), O que faz o brasil, Brasil? Rio de Janeiro, Rocco.

GEERTZ, Clifford. "Transição para Humanidade". In: O Papel da Cultura nas Ciências Sociais. Porto Alegre: Editorial Vila Martha, 1980.

HALL, Stuart. A Identidade Cultural na Pós-modernidade. Tradução Toma Tadeu da Silva. Guaracira Lopes Louro. 10 ed. Rio de Janeiro: DP \& A, 2005.

MATOS, Maria Izilda. Por uma história da mulher. São Paulo: EDUSC, 2000.

PEDRO, Joana Maria. Los sentimentos del feminismo. In: GARCIA, Gerardo Necoechea; MONTENEGRO, Antonio Torres (Compiladores). Caminos de historia y memoria en América Latina. Buenos Aires: Imago Mundi, 2011.

PEREIRA, Mariana Cunha. A Ponte Imaginária: o trânsito interétnico na fronteira Brasil - Guiana. (Tese Doutorado) - CEPPAC/UnB, 2005.

PESAVENTO, Sandra Jatahy. História \& História Cultural. 2ª ${ }^{a}$ ed. Belo Horizonte: Autêntica, 2005.

SCOTT, Joan Gênero: uma categoria de análise histórica. 3ª . ed. Recife: SOS CORPO, 1996.

SAYAD, Abdelmalek. A imigração ou os paradoxos da alteridade. São Paulo: Editora da Universidade de São Paulo, 1998.

TEDESCHI, Losandro Antonio. Os estudos de gênero e os processos de construção da interculturalidade. In: TEDESCHI, Losandro Antonio (org.) Identidades e as narrativas de gênero: reflexões sobre os processos de construção da interculturalidade. Dourados:-MS: Ed. UFGD, 2013. 